\title{
Studies on Phospholipids
}

\section{DETERMINATION OF ETHANOLAMINE AND SERINE*}

\author{
By F. D. COLLINS and L. W. WHEELDON \\ Department of Biochemistry, John Curtin School of Medical Research, \\ The Australian National University, Canberra, A.C.T. Australia
}

(Received 22 October 1957)

A reliable and sensitive method for the determination of ethanolamine and serine, the bases present in kephalin, is necessary in the study of phospholipid metabolism. The procedure described by Artom (1945) is reliable but not sensitive (range 10-50 $\mu$ moles), whereas that described by Levine \& Chargaff (1951) is sensitive (range $0 \cdot 1-0.3 \mu \mathrm{mole}$ ) but unreliable. The method devised by Axelrod, Reichenthal \& Brodie (1953) involves the hydrolysis of the fat, the reaction of the free bases with 1-fluoro-2:4-dinitrobenzene (FDNB), the separation of the $N$-dinitrophenyl (DNP) bases and their quantitative estimation by their light absorption at a wavelength at which FDNB does not interfere. The present paper describes a method which involves the reaction of the lipids with FDNB, the complete removal of excess of reagents, the hydrolysis of the DNP-lipids and the determination of DNP-ethanolamine and DNP-serine by a differential colour reaction which does not involve their separation.

\section{MATERIALS}

All solvents used were reagent grade. The tetramethylammonium hydroxide was used as supplied as a $25 \%(\mathrm{w} / \mathrm{v})$ solution in water. DNP-ethanolamine and DNP-serine were prepared as described by Wheeldon \& Collins (1957).

N-(2:4-Dinitrophenyl)-ethanolamine-0-phosphoric acid. This was prepared by treating ethanolamine- $O$-phosphoric acid (423 mg.) (Californian Foundation for Biochemical Research) with FDNB (700 mg.) and $\mathrm{NaHCO}_{3}(1 \mathrm{~g}$. in $20 \mathrm{ml}$. of water). The mixture was left at $20^{\circ}$ for $16 \mathrm{hr}$. in the dark and extracted with diethyl ether. The aqueous layer was cooled and acidified with $10 \mathrm{~N}-\mathrm{HCl}$ until an oil separated. This solidified at $-10^{\circ}$ and crystallized from ethanol. The yield was 0.24 g., m.p. $163-165^{\circ}$ (uncorr.) (Found: C, 31.7; $\mathrm{H}, 3 \cdot 4 ; \mathrm{N}, 13 \cdot 0 ; \mathrm{P}, 9 \cdot 6 . \mathrm{C}_{8} \mathrm{H}_{10} \mathrm{O}_{8} \mathrm{~N}_{3} \mathrm{P}$ requires $\mathrm{C}, 31.3 ; \mathrm{H}, 3.3 ; \mathrm{N}, 13.7 ; \mathrm{P}, 10.1 \%$ ). In $0.1 \mathrm{~N}-\mathrm{HCl}$ $\lambda_{\text {max. }}$ was at $350 \mathrm{~m} \mu \quad(\epsilon=15500)$. On paper chromatography a single spot was obtained.

N-(2:4-Dinitrophenyl)-serine-0-phosphoric acid. This was prepared by treating serine-O-phosphoric acid monohydrate (406 mg.) (Californian Foundation for Biochemical Research) with FDNB (1 g.) and $\mathrm{NaHCO}_{3}(1.5 \mathrm{~g}$. in $30 \mathrm{ml}$. of water). The mixture was left for $16 \mathrm{hr}$. at $20^{\circ}$ in the dark.

\footnotetext{
* Part 3: Wheeldon \& Collins (1958).
}

The solution was then extracted with diethyl ether to remove excess of FDNB, acidified (pH 5) with $10 \mathrm{~N}-\mathrm{HCl}$ and concentrated to a syrup in vacuo. The free acid did not crystallize readily but on the addition of an equimolecular amount of triethylamine the salt was crystallized from propan-2-ol. The yield was 0.40 g., m.p. $147^{\circ}$ (uncorr.) (Found: C, 39.1; H, 5.9; N, 12.0; P, 7.2. $\mathrm{C}_{9} \mathrm{H}_{10} \mathrm{O}_{10} \mathrm{~N}_{8} \mathrm{P}$, $\mathrm{C}_{6} \mathrm{H}_{15} \mathrm{~N}$ requires $\mathrm{C}, 39.9 ; \mathrm{H}, 5.5 ; \mathrm{N}, 12.4 ; \mathrm{P}, 6.9 \%$ ). In $0 \cdot 1 \mathrm{~N}-\mathrm{HCl} \lambda_{\max }$ was at $350 \mathrm{~m} \mu \quad(\epsilon=14900)$. On paper chromatography a single spot was obtained.

\section{METHODS}

The extraction of the lipids and their dinitrophenylation was carried out as described by Wheeldon \& Collins (1957).

Paper chromatography. Ascending chromatography of the DNP-bases was carried out on Whatman no. 1 paper either with $\mathrm{M}-\mathrm{NaH}_{2} \mathrm{PO}_{4}$ and $0.5 \mathrm{M}-\mathrm{Na}_{2} \mathrm{HPO}_{4}$ (Levy, 1954) or with tert.-pentanol-pyridine-water (5:1:5, by vol.).

\section{RESULTS}

Hydrolysis of N-(2:4-dinitrophenyl)-lipids. The most satisfactory medium for hydrolysis of the DNP-lipids was ethanolic $\mathrm{N}-\mathrm{HCl}$; hydrolysis was complete in $3 \mathrm{hr}$. at $100^{\circ}$. Table 1 shows that the recoveries of total DNP-bases after hydrolysis of DNP-lipids were quantitative. The hydrolysis procedure was complicated by the fact that DNP. serine in ethanolic $\mathrm{N}-\mathrm{HCl}$ formed the ethyl ester and that DNP-serine was light-sensitive. The

Table 1. Recovery of N-(2:4-dinitrophenyl)-bases after the hydrolysis of $\mathrm{N}$-(2:4-dinitrophenyl)-lipids

DNP-lipids were hydrolysed by heating with $\mathrm{N}-\mathrm{HCl}$ in ethanol for $3 \mathrm{hr}$. The amount of DNP-bases was determined from the light absorption; DNP-lipids were measured in light petroleum and the free DNP-bases were measured in water after removing the fatty acids.

\begin{tabular}{|c|c|c|c|}
\hline \multirow[b]{2}{*}{ Lipid } & \multicolumn{2}{|c|}{ DNP-base ( $\mu$ mole $\diamond)$} & \multirow[b]{2}{*}{$\begin{array}{c}\text { Recovery } \\
(\%)\end{array}$} \\
\hline & $\begin{array}{c}\text { Before } \\
\text { hydrolysis }\end{array}$ & $\begin{array}{c}\text { After } \\
\text { hydrolysis }\end{array}$ & \\
\hline ep brain & $\begin{array}{r}6 \cdot 0 \\
32 \cdot 6\end{array}$ & $\begin{array}{r}5 \cdot 9 \\
32 \cdot 3\end{array}$ & $\begin{array}{l}98 \\
99\end{array}$ \\
\hline $\mathrm{ra}$ & 60.5 & $61 \cdot 3$ & 101 \\
\hline & 3.7 & 3.4 & 92 \\
\hline & $8 \cdot 3$ & 8.7 & 105 \\
\hline
\end{tabular}


solutions were shielded from light. As the ethyl ester of DNP-serine could not be distinguished from DNP-ethanolamine in the colour reaction to be described the initial hydrolysis in ethanolic $\mathrm{N}-\mathrm{HCl}$ was followed by hydrolysis in aqueous $\mathrm{N}$ HCl. The bases present, after hydrolysis, were identified by paper chromatography. In no case were there more than $2 \%$ of DNP-compounds other than DNP-ethanolamine and DNP-serine, and these impurities were in the positions expected for the corresponding phosphoric acid derivatives. The amounts present were estimated by cutting out the spots, and eluting with water and measuring the absorption at $350 \mathrm{~m} \mu$. Table 2 gives the $R_{F}$ values for the DNP-bases and the phosphoric acid derivatives.

Colour reaction for N-(2:4-dinitrophenyl)-bases. Porter (1955) described the reaction between tetramethylammonium hydroxide dissolved in dimethylformamide and various nitroderivatives of aromatic compounds. DNP-ethanolamine and DNP-serine in this system gave rise to coloured ions with $\lambda_{\max }$ at $430 \mathrm{~m} \mu$ having dissociation constants of 0.1 and $6 \mathrm{~mm}$ respectively and which on the addition of $20 \%(\mathrm{v} / \mathrm{v})$ ethanol became $3 \mathrm{mM}$ and $0.2 \mathrm{M}$ respectively. Fig. 1 shows the effect of varying concentrations of tetramethylammonium hydroxide on the values of the molecular-extinction coefficient at $500 \mathrm{~m} \mu$. At a concentration of quaternary base of $27 \mathrm{~mm}$ the DNP-ethanolamine is completely ionized whereas the DNP-serine is only $10 \%$ ionized, and this difference forms the basis of the present method. Fig. 2 shows the absorption spectra of the two DNP-bases under these conditions and demonstrates that $500 \mathrm{~m} \mu$ is a convenient wavelength to use. Measurements at $393 \mathrm{~m} \mu$, where the two compounds have the same molecular-extinction coefficient, enable the combined concentration of the DNP-bases to be calculated.

The reliability of the colorimetric procedure depends on the concentration of tetramethylammonium hydroxide being the same for unknown and for standards. In a hydrolysate of a DNP-lipid the

Table 2. $R_{p}$ values for some N-(2:4-dinitrophenyl)bases related to $\mathrm{N}-(2: 4-d i n i t r o p h e n y l)-l i p i d s$

The solvent system used was $A$, that described by Levy (1954) or $B$, tert.-pentanol-pyridine-water (5:1:5, by vol.). Whatman no. 1 paper was used in an ascending system. Time of run, $18 \mathrm{hr}$.

DNP-ethanolamine DNP-serine

DNP-ethanolamine-O-phosphoric acid DNP-serine- $O$-phosphoric acid

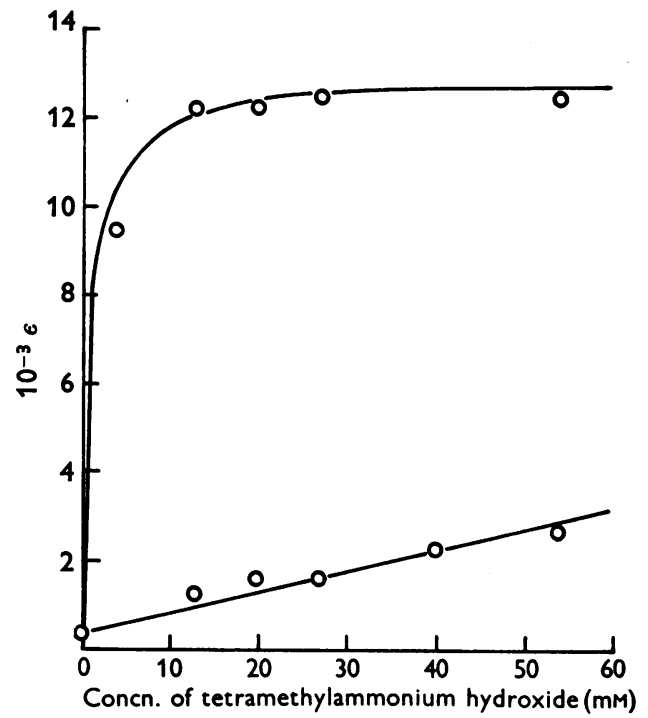

Fig. 1. Colour development and concentration of quaternary base. Molecular-extinction coefficients at $500 \mathrm{~m} \mu$ of DNP-ethanolamine and DNP-serine were measured in dimethylformamide-thanol $(4: 1, \nabla / \nabla)$ and known amounts of tetramethylammonium hydroxide. Theoretical curves have been calculated assuming a dissociation constant of $3 \mathrm{~mm}$ for DNP-ethanolamine (upper curve) and of $0.2 \mathrm{M}$ for DNP-serine (lower curve); experimental values are indicated by the circles.

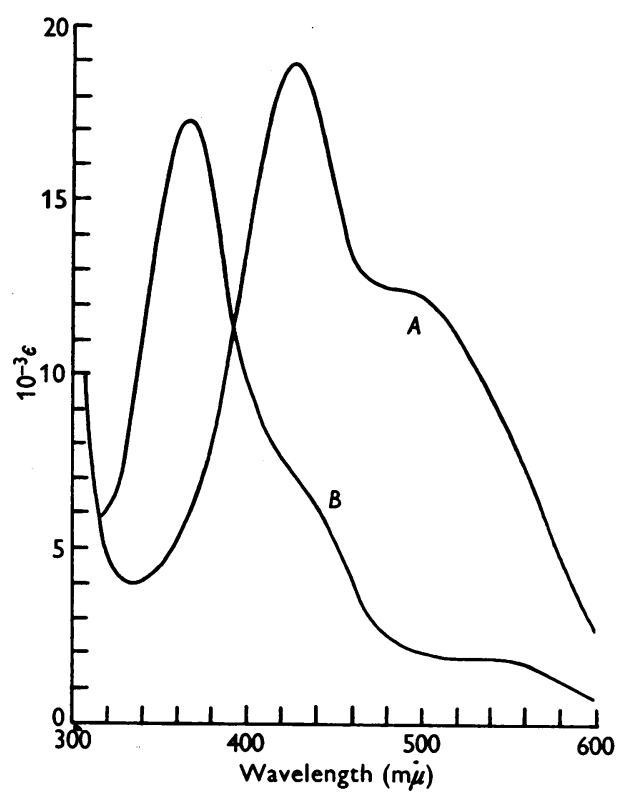

Fig. 2. Absorption spectra of DNP-ethanolamine and DNP-serine in 27 mM-tetramethylammonium hydroxide. DNP-ethanolamine (curve $A$ ) and DNP-serine (curve $B$ ) were dissolved in a mixture of dimethylformamideethanol- $n$-butylamine (4:1:0.04, by vol.). 
water-soluble fraction will contain, in addition to the DNP-bases, phosphoric acid, glycerophosphoric acid, inositol phosphoric acid, choline phosphate or chloride and free hydrochloric acid. The last component is removed by evaporation in vacuo. If the concentration of tetramethylammonium hydroxide were to change by $10 \%$, i.e. from 27 to $24 \mathrm{~mm}$, it can be calculated from the equations given below and from the data in Fig. 1 that the error introduced into the method will not exceed $2 \%$. This change in concentration could be caused by the presence of $30 \mu \mathrm{g}$.equivalent of acid (or $15 \mu$ g.atoms of $\mathrm{P}$ ) in the hydrolysate, and the sample of hydrolysate taken for analysis should not contain more than $15 \mu$ g.atoms of $P$.

The addition of $0.8 \%(\mathrm{v} / \mathrm{v})$ of $n$-butylamine to the solvent system was found to assist in buffering the solution.

\section{Determination of ethanolamine and serine in lipids}

On the basis of the foregoing results the following procedure is recommended. The lipids are obtained from the tissues and dinitrophenylated as described by Wheeldon \& Collins (1957). A quantity of DNP-lipid which corresponds to between 0.1 and $1.5 \mu$ moles of amino $N$ is dissolved in $5 \mathrm{ml}$. of ethanolic $\mathrm{N}-\mathrm{HCl}$ and hydrolysed by boiling under reflux for $3 \mathrm{hr}$. The hydrolysate is evaporated to dryness in vacuo, $2 \mathrm{ml}$. of $\mathrm{N}-\mathrm{HCl}$ is added and the mixture is again refluxed for a further $3 \mathrm{hr}$. After adding about $0.1 \mathrm{~g}$. of Hyflo Supercel the mixture is filtered, the filter is washed with $5 \mathrm{ml}$. of water and the filtrate is reduced to dryness by heating in vacuo. The residue is dissolved in $10 \mathrm{ml}$. of a mixture of dimethylformamide-ethanol- $n$-butylamine (4:1:0.04, by vol.), $0.1 \mathrm{ml}$. of $25 \%(w / v)$ tetramethylammonium hydroxide is added and, after mixing, the extinctions are measured at 393 and $500 \mathrm{~m} \mu$. If $e$ and $s$ respectively represent the amounts of DNP-ethanolamine and DNP-serine in $\mu$ moles in the $10.1 \mathrm{ml}$. of solution and if $E_{1}$ and $E_{2}$ represent the extinctions respectively at $393 \mathrm{~m} \mu$ and at $500 \mathrm{~m} \mu$ then it follows that $E_{1}=a e / 1 \cdot 01+b s / 1.01$ and $E_{2}=c e / 1 \cdot 01+d s / 1 \cdot 01$. The constants $a, b, c$ and $d$ are equal to $10^{-4}$ times the molecular-extinction coefficients; the mean values and standard errors (12 determinations) are: $a, 1 \cdot 13 \pm 0.007 ; b, 1 \cdot 13 \pm 0 \cdot 007 ; c, 1 \cdot 23 \pm 0.007$ and $d, 0 \cdot 184 \pm 0 \cdot 006$. Hence

$$
\begin{aligned}
& e=0.965 E_{2}-0.157 E_{1} ; \\
& s=1.05 E_{1}-0.965 E_{2} ; \\
& e+s=0.894 E_{1} \\
& e /(e+s)=1.18-1.08 E_{2} / E_{1} .
\end{aligned}
$$

and

The recoveries from mixtures of known amounts of DNP-ethanolamine and of DNP-serine are shown in Table 3. Known amounts of DNP-serine were added to hydrolysates of guinea-pig lipids and, as shown in Table 4, the average recovery was $104.5 \%$.

Reaction of other N-(2:4-dinitrophenyl)-compounds. The phosphoric acid derivatives of DNP-ethanolamine and DNP-serine, and dinitrophenylated lipids, gave $\lambda_{\max }$ at $365 \mathrm{~m} \mu$ in the colour test whereas the methyl ester of DNP-serine, and methylated and dinitrophenylated lipids (Collins \& Wheeldon, 1957), gave $\lambda_{\max }$ at $430 \mathrm{~m} \mu$.

Occurrence of ethanolamine and serine in some lipids. The proportions of ethanolamine and serine were determined on a number of lipids, with the results shown in Table 5.

\section{DISCUSSION}

The method described in this paper for the determination of serine and ethanolamine has certain features in common with the procedure described by Axelrod et al. (1953). Although it is as convenient to treat the lipid with FDNB before hydrolysis as afterwards (cf. Axelrod et al. 1953), the former procedure has the advantage that removal of the excess of reagents is readily

Table 3. Application of the colour reaction to mixtures of N-(2:4-dinitrophenyl)-ethanolamine and

\begin{tabular}{|c|c|c|c|}
\hline \multicolumn{2}{|c|}{ DNP-serine } & \multicolumn{2}{|c|}{ DNP-ethanolamine } \\
\hline Added & Found & Added & Found \\
\hline $\begin{array}{l}0.84 \\
0.56 \\
0 \cdot 28\end{array}$ & $\begin{array}{l}0 \cdot 85 \\
0 \cdot 60 \\
0 \cdot 32\end{array}$ & $\begin{array}{l}0.24 \\
0.48 \\
0 \cdot 72\end{array}$ & $\begin{array}{l}0 \cdot 23 \\
0 \cdot 47 \\
0 \cdot 72\end{array}$ \\
\hline
\end{tabular}
$\mathrm{N}$-(2:4-dinitrophenyl)-serine

Known amounts of DNP-ethanolamine and DNPserine were mixed and analysed. All figures are in $\mu$ mole.

Table 4. Recoveries of N-(2:4-dinitrophenyl)-serine added to hydrolysates of $\mathrm{N}$-(2:4-dinitrophenyl)-lipids

DNP-lipids prepared from guinea-pig tissues were hydrolysed and the DNP-bases determined before and after adding known amounts of DNP-serine. All figures in $\mu$ mole.

\begin{tabular}{lcccc} 
& & \multicolumn{3}{c}{ DNP-serine } \\
\cline { 3 - 5 } Lipid & $\begin{array}{c}\text { DNP. } \\
\text { ethanolamine }\end{array}$ & $\begin{array}{ccc}\text { In } \\
\text { sample }\end{array}$ & Added & Recovered \\
Brain & 0.47 & 0.06 & 0.22 & 0.24 \\
Kidney & 0.58 & 0.06 & 0.22 & 0.22 \\
Liver & 0.85 & 0.10 & 0.11 & 0.13 \\
Heart & 0.37 & 0.06 & 0.11 & 0.10 \\
\hline
\end{tabular}

Table 5. Ethanolamine and serine contents of some lipids

All figures are $\mu$ moles $/ 100 \mathrm{mg}$. of lipid.

Source

Guinea-pig kidney

Ethanolamine

Serine

Guinea-pig liver

12

21

$1 \cdot 4$

Guinea-pig heart

Guinea-pig brain

$2 \cdot 6$

Rat brain

Sheep brain

Egg yolk

A serine-rich fraction of ox-brain lipids
11 
accomplished. Further, the use of a differential colour reaction is less time-consuming than alternative methods which involve separation of the two DNP-bases (cf. Axelrod et al. 1953).

In the rare instances where more than two DNP. bases are present, as, for example, in Neurospora lipids, which contain ethanolamine, serine and 1-amino-2-methylpropan-2-ol (Ellman \& Mitchell, 1954), the procedure described by Levy (1954) for DNP-amino acids can be used. When this method was applied to a mixture of DNP-ethanolamine and DNP-serine the recovery was good (98\%) but the colorimetric method was quicker.

The experimental results on the application of the colour test to the DNP-bases suggest that the acidic group in the DNP-serine is responsible for the difference in the dissociation constants of the coloured forms. This is confirmed by the fact that the ethyl ester of DNP-serine reacts like DNP. ethanolamine and that DNP-ethanolamine- $O$ phosphoric acid reacts like DNP-serine. These observations also explain why the colour reaction with DNP-lipids simulates DNP-serine and methylated DNP-lipids simulate DNP-ethanolamine, as in the first case the phosphoric acid groups are free and in the second case they are in the form of methyl esters.

The procedure described in this paper was developed as an adjunct to the study of DNP. lipids (Collins \& Wheeldon, 1957) but, if used in conjunction with the method described by Wheeldon \& Collins (1957) for total amino $\mathrm{N}$, should be of wide applicability.

\section{SUMMARY}

1. A method depending on a differential colour reaction for the determination of ethanolamine and serine in phospholipids is described.

2. The advantages of the method, as compared with those of other methods, are discussed.

Our thanks are due to Mrs M. Labutis for her technical assistance.

\section{REFERENCES}

Artom, C. (1945). J. biol. Chem. 157, 585.

Axelrod, J., Reichenthal, J. \& Brodie, B. B. (1953). J. biol. Chem. 204, 903.

Collins, F. D. \& Wheeldon, L. W. (1957). Biochem. J. 66, 441.

Ellman, G. L. \& Mitchell, H. K. (1954). J. Amer. chem. Soc. 76, 4028.

Levine, C. \& Chargaff, E. (1951). J. biol. Chem. 192, 465.

Levy, A. L. (1954). Nature, Lond., 174, 126.

Porter, C. C. (1955). Analyt. Chem. 27, 805.

Wheeldon, L. W. \& Collins, F. D. (1957). Biochem. J. 66, 435.

Wheeldon, L. W. \& Collins, F. D. (1958). Biochem. J. 70, 43.

\title{
Substrates for Rumen $\beta$-Glucosidase
}

\author{
By G. N. FESTENSTEIN \\ The Rowett Research Institute, Bucksburn, Aberdeenshire
}

(Received 27 January 1958)

Substrates used for $\beta$-glucosidase include natural products such as cellobiose and salicin as well as synthetic compounds like the nitrophenyl glucosides (Aizawa, 1939; Conchie, 1954). Enzyme extracts from single micro-organisms have been shown to vary in their specificities. Jermyn (1952) separated eight components in an Aspergillus oryzae extract, with varying degrees of specificity towards different substrates, whereas a Stachybotrys atra preparation hydrolysed $p$-nitrophenyl $\beta$-glucoside but not $o$-nitrophenyl $\beta$-glucoside or cellobiose (Jermyn, 1955). Differences in relative cellobiase and salicinase activities in preparations from different sources were observed by Grassmann, Zechmeister, Tóth \& Stadler (1933) and Reese \& Levinson (1952). Barnett, Ingram \& Swain (1956) studied the $\beta$-glucosidase activity of different yeasts and found that all split aesculin, but many would not split any one of arbutin, salicin or cellobiose. In the present investigation $o$-nitrophenyl $\beta$-glucoside, cellobiose and salicin have been used in a comparative study of $\beta$ glucosidase activity from cell-free extracts of mixed micro-organisms from sheep rumen.

\section{EXPERIMENTAL}

Materials. o-Nitrophenyl $\beta$-D-glucoside was kindly provided by $\mathrm{Dr}$ J. Conchie. Cellobiose (shown to be chromatographically pure) and glucono-1:4-lactone were obtained from L. Light and Co. Ltd., salicin from Hopkins and Williams Ltd., glucose oxidase from Sigma Chemical Co., and peroxidase from C. F. Boehringer und Soehne.

$\beta$-Glucosidase preparations. These were produced by butanol extraction of sheep-rumen micro-organisms centrifuged at $1500 \mathrm{~g}$, as described previously (Festenstein, 1958). 